\title{
Efektivitas Peer Reading terhadap Kemampuan Pemahaman Dokkai Bahasa Jepang
}

\author{
Rina Sukmara \\ Universitas Muhammadiyah Prof. DR. HAMKA, Indonesia \\ rinasukmara2017@gmail.com
}

DOI: $10.18196 /$ jjlel.4242

\begin{abstract}
Abstrak
Tujuan dari penelitian ini adalah untuk mengetahui efektivitas metode peer reading terhadap kemampuan pemahaman dokkai pada mahasiswa semester 3 Program Studi Pendidikan Bahasa Jepang FKIP UHAMKA. Metode peer reading termasuk dalam metode Peer Learning yaitu pembelajaran yang dilakukan bersama rekan sebaya. Penelitian ini menggunakan metode eksperimen semu dengan sample penelitian mahasiswa semester 3 Program Studi Pendidikan Bahasa Jepang FKIP UHAMKA. Berdasarkan tabel paired sample test dengan menggunakan SPSS didapat nilai sig 0,000 di bawah dari taraf signifikansi 0,005 maka perbedaan antara nilai pre test dan post test antara sebelum dan sesudah penerapan metode Peer reading terhadap hasil kemampuan pemahaman wacana Bahasa Jepang (Dokkai) signifikan. Berdasarkan hasil uji gain nilai pre test dan post test, nilai pre test sebelum diberikan treatment adalah 0,41 maka rata rata nilai dokkai mahasiswa naik sehingga dapat disimpulkan bahwa metode Peer reading efektif terhadap pemahaman dokkai pada mahasiswa semester 3 Program Studi Pendidikan Bahasa Jepang FKIP UHAMKA.
\end{abstract}

Kata kunci: dokkai; metode; peer learning; peer reading

\begin{abstract}
(The Effectiveness of Peer Reading in the Japanese Dokkai) The purpose of this research was to determine the effectiveness of the peer reading method in dokkai learning applied for the sophomore students of Japanese Language Study Program, FKIP UHAMKA. Peer reading method was included into peer learning, the learning method done by peer students. The research used a quasiexperimental method. The sample of this research was the sophomore students of the Japanese Language Education Study Program, FKIP UHAMKA. Based on the paired sample test, using SPSS, it was gained the sig value of 0.000 which
\end{abstract}


was smaller than the significance level of 0.005, it meant that there was a significant difference between the pre-test and post-test scores before and after the implementation of the Peer reading method to the results of Japanese language reading ability (Dokkai). Based on the results of the average pre-test and post-test scores, the gain score was 0.41, so it could be concluded that the Peer reading method was effective applied in dokkai learning for the sophomore students of the Japanese Language Study Program, FKIP UHAMKA.

Keywords: dokkai; method; peer learning; peer reading

\section{PENDAHULUAN}

Dalam berbahasa, keterampilan mendengar (menyimak), membaca dan menulis serta berbicara sangat diperlukan agar mampu berkomunikasi dengan baik dan tepat. Keterampilan tersebut saling berkaitan dalam berkomunikasi maupun interaksi (Kusmayadi, 2008: 10). Tahapan pertama dalam keterampilan berbahasa adalah menyimak. Menyimak menurut Tarigan (dalam Kartini, 2012) menyimak merupakan kegiatan perhatian, pemahaman, interpretasi maupun apresiasi melalui mendengarkan untuk mendapat informasi dari bahan yang disimak. Kemudian menyimak menurut Mulyati (Mulyati, 2014) menjelaskan menyimak merupakan kegiatan menemukan makna dari bahan yang didengar. Membaca menurut Tarigan (Tarigan, 1986) membaca merupakan proses yang digunakan untuk mendapat maksud yang terdapat pada media. Agar mahasiswa agar terasah keterampilan berbahasa terutama membaca, dalam kurikulum Pendidikan Bahasa Jepang Universitas Muhammadiyah Prof. DR. HAMKA terdapat mata kuliah dokkai yang merupakan mata kuliah yang berhubungan, dari semester II sampai dengan semester IV. Ada beberapa jenis tingkatan dokkai yang dipelajari antara lain; Shokyu Dokkai untuk tingkatan dasar di semester II, Chukyu Dokkai untuk tingkatan menengah di semester III, dan Chujokyu Dokkai untuk tingkatan menegah atas di semester IV. Mata kuliah dokkai yang dipelajari oleh mahasiswa semester III yaitu Chukyu Dokkai. Mata kuliah ini merupakan ajang pelatihan dasar menyimak berbagai wacana singkat yang di dalamnya terdapat pola kalimat, kosa kata, ungkapan serta tema- 
tema tentang Jepang. Pembelajaran dalam mata kuliah ini mengarah pada penguasaan keterampilan membaca dan menyimak secara integratif pada tingkat menengah. untuk bisa memahami dengan baik makna yang terdapat di dalam kalimat yang ada pada sebuah teks bacaan mahasiswa di haruskan menguasai beberapa kosakata dan kanji yang terdapat di dalam isi cerita tersebut. Karena isi di dalam cerita menggunakan huruf hiragana, katakana, dan kanji.

Pembelajaran Dokkai merupakan pembelajaran mengenai pemahaman terhadap suatu teks berbahasa jepang. Pembelajaran Dokkai merupakan salah satu pembelajaran dalam bahasa jepang yang diperlukan karena Dokkai merupakan aspek keterampilan yang penting untuk mempelajari bahasa. Menurut Richard dkk (dalam Harras, 2011), bahwa membaca adalah memahami maksud isi yang terkandung dalam tulisan dan teks. Dalam mempelajari dokkai yang paling penting yaitu mengingat berbagai macam kosakata dan kanji. Namun setiap orang memiliki kekurangannya masing-masing dalam hal mengingat dan memahami. Memahami suatu cerita membutuhkan waktu yang cukup lama apabila mahasiswa kurang menguasai kosakata dan kanji, sehingga diperlukan metode pembelajaran yang tepat untuk agar mahasiswa memahami isi sebuah teks bacaan.

Teori Peer reading selalu berhubungan dengan teori Peer Learning. Menurut Tateoka (dalam Rasiban \& Dianasari, 2017), Peer Learning secara harfiah yaitu 'Peer' adalah teman dan 'Learning' adalah belajar, jika dilihat dari penerapannya, Peer Learning merupakan cara belajar bekerjasama antar sesama pembelajar. Kerjasama adalah yang menjadi konsep proses pembelajaran dengan peer learning karena setiap individu yang terlibat harus menunjukkan kreativitas dan kesamaan dalam kemampuan. Peer reading menjadi kegiatan untuk saling berbagi informasi dan pemahaman terhadap bahan baca dengan pembelajar lain. Saling menyebutkan pemahaman antara pembelajar satu dengan yang lain menggunakan bahasa 
kedua untuk mendapatkan hasil yang baik dalam pelaksanaannya. Peer reading termasuk bagian dari peer learning dimana ada bagian lain selain peer reading dalam peer learning seperti peer review dalam kemampuan menulis dan peer listening dalam kemampuan mendengar.

Peer learning menjadikan pengajar sebagai fasilitator dalam kegiatan pembelajaran serta menjadikan proses pembelajaran student-center sedangkan dalam pembelajaran konvensional pengajar sendiri menjadi pusat dari kegiatan pembelajaran.

\section{METODE PENELITIAN}

Quantitative research merupakan pendekatan pada penelitian ini serta dengan memakai metode penelitian eksperimen semu, Penelitian ini diujicobakan dengan cobakan metode Peer reading terhadap mata kuliah Dokkai, pada mahasiswa semester III dengan sample mahasiswa semester III Program Studi Pendidikan Bahasa Jepang FKIP UHAMKA sebanyak 36 orang. Waktu pelaksanaan penelitian yakni dimulai dari bulan November 2019 sampai dengan Pebruari 2020. variabel yang digunakan dalam penelitian ini adalah variabel bebas (X) dan variabel terikat (Y). Variabel bebas ( X) yaitu Metode Peer reading dan Variabel terikat (Y) yaitu Kemampuan menyimak (dokkai).

\section{HASIL DAN PEMBAHASAN}

a. Statistika Deskriptif Pretest

\begin{tabular}{lrrrrr}
\hline \multicolumn{5}{c}{ Descriptive Statistics } & \\
\hline & N & Minimum & Maximum & Mean & $\begin{array}{c}\text { Std. } \\
\text { Deviation }\end{array}$ \\
\hline Nilai_Pretest & 19 & 60 & 86 & 70.84 & 8.207 \\
\hline $\begin{array}{l}\text { Valid N } \\
\text { (listwise) }\end{array}$ & 19 & & & & \\
\hline
\end{tabular}


Berdasarkan perhitungan dengan SPSS statistik deskriptif pretest didapat rata-rata hasil pretest adalah 70.84, rentang jarak skor terkecil dengan terbesar atau range adalah 26, skor minimum pretest 60 , skor maksimum 86, jumlah semua hasil skor pretest siswa 1346, standar deviasi atau sebaran data dalam sampel terhadap rata-rata adalah 8.207.

b. Statistika Deskriptif Posttest

\begin{tabular}{lrrrrr}
\hline \multicolumn{5}{c}{ Descriptive Statistics } & \\
\hline & N & Minimum & Maximum & Mean & $\begin{array}{c}\text { Std. } \\
\text { Deviation }\end{array}$ \\
\hline Nilai_Posttest & 19 & 67 & 100 & 82.42 & 10.079 \\
\hline $\begin{array}{l}\text { Valid N } \\
\text { (listwise) }\end{array}$ & 19 & & & & \\
\hline
\end{tabular}

Tabel 2. Statistik Deskriptif Posttest

Berdasarkan perhitungan dengan SPSS statistik deskriptif pretest didapat rata-rata hasil pretest adalah 82.42, rentang jarak skor terkecil dengan terbesar atau range adalah 33, skor minimum pretest 67, skor maksimum 100, jumlah semua hasil skor pretest siswa 1566, standar deviasi atau sebaran data dalam sampel terhadap rata-rata adalah 10.079.

c. Uji Normalitas Pretest Dan Posttest

\begin{tabular}{lrrrrrrr}
\hline & \multicolumn{7}{c}{ Tests of Normality-PreTest } \\
\hline & \multicolumn{2}{c}{ Kolmogorov-Smirnov ${ }^{\mathrm{a}}$} & \multicolumn{3}{c}{ Shapiro-Wilk } \\
\hline Statistic & $\mathrm{df}$ & \multicolumn{1}{c}{ Sig. } & Statistic & $\mathrm{df}$ & Sig. \\
\hline Nilai_Pretest & .172 & 19 & .139 & .932 & 19 & .187 \\
\hline Nilai_Posttest & .138 & 19 & $.200^{*}$ & .952 & 19 & .425 \\
\hline
\end{tabular}

Tabel 3. Uji Normalitas 
Pada hasil analisis pada SPSS diketahui nilai signifikansi shapiro wilk didapat 0.187 untuk pretest dan 0.429 untuk posttest diatas 0.05 (sebagai taraf signifikansi), sehingga variabel berdistribusi normal.

d. Uji Homogenitas

\begin{tabular}{|c|c|c|c|c|c|}
\hline \multicolumn{6}{|c|}{ Test of Homogeneity of Variances } \\
\hline \multicolumn{6}{|c|}{$\begin{array}{l}\text { Levenne } \\
\end{array}$} \\
\hline & & Statistic & df1 & df2 & Sig. \\
\hline \multirow[t]{4}{*}{ Hasil } & Based on Mean & 1.011 & 1 & 36 & .321 \\
\hline & Based on Median & 1.007 & 1 & 36 & .322 \\
\hline & $\begin{array}{l}\text { Based on Median and } \\
\text { with adjusted df }\end{array}$ & 1.007 & 1 & 35.995 & .322 \\
\hline & $\begin{array}{l}\text { Based on trimmed } \\
\text { mean }\end{array}$ & 1.061 & 1 & 36 & .310 \\
\hline
\end{tabular}

Tabel 4. Uji Homogenitas

Berdasarkan hasil output SPSS dapat diketahui nilai signifikansi lebih tinggi dari taraf signifikansi yaitu $0.321>0,05$, artinya data pretest dan posttest memiliki varian yang homogen.

e. Uji Hipothesis

Pengujian Hipotesis penelitian ini menggunakan Uji t dan nilai gain ternormalisasi. Uji t yang dipakai untuk menguji apakah hasil dalam pretest dan post-test memiliki perbedaan signifikan terjadi pada hasil belajar. Untuk melakukan uji-t, digunakan uji paired sample t test dengan nilai signifikansi 0,05 serta data harus normal dan bervariasi homogen. 


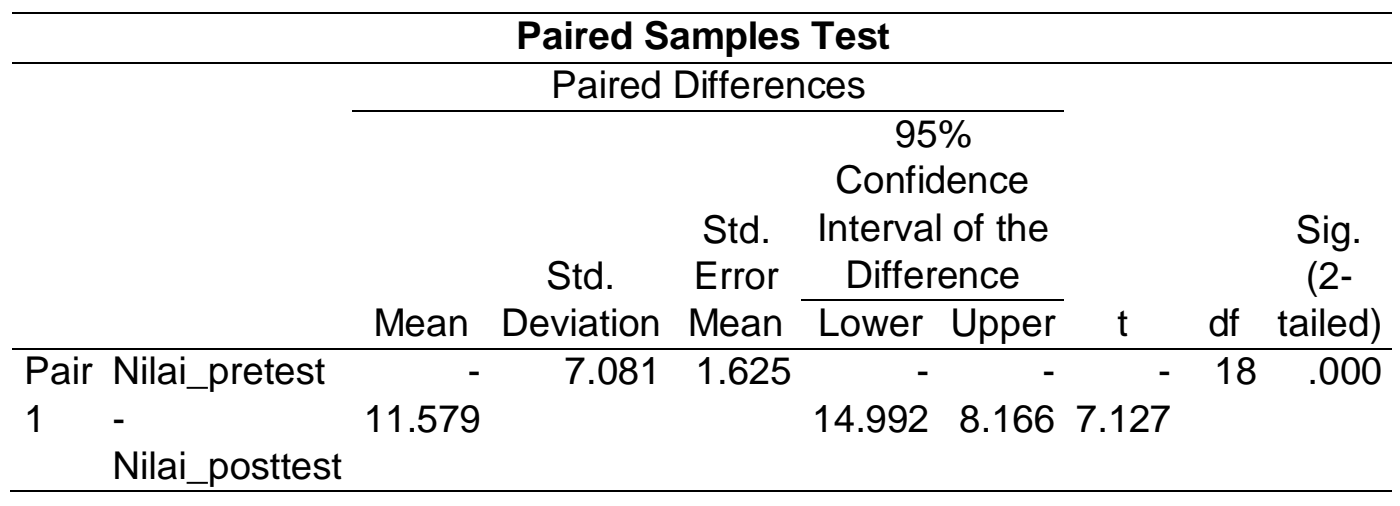

Tabel 5. Pengujian T test

Berdasarkan hasil output SPSS didapat nilai median sebesar 0.000 artinya terdapat kecenderungan kenaikan skor sesudah perlakuan. Rata-rata kenaikannya adalah 7.127.

Berdasarkan tabel paired sample test dengan menggunakan SPSS didapat nilai sig 0,000. Jika nilai sig. dibawah dari nilai taraf signifikan maka terjadi perbedaan signifikan antara sebelum dan sesudah penerapan metode Peer reading terhadap kemampuan pemahaman wacana Bahasa Jepang (Dokkai). Karena nilai sig $=0,000$ dibawah 0,005 maka perbedaan sesudah penerapan metode Peer reading terhadap kemampuan pemahaman wacana Bahasa Jepang (Dokkai) signifikan. Dapat dilihat perbedaan dari rata rata nilai pre test dan post test pada Gambar.1:

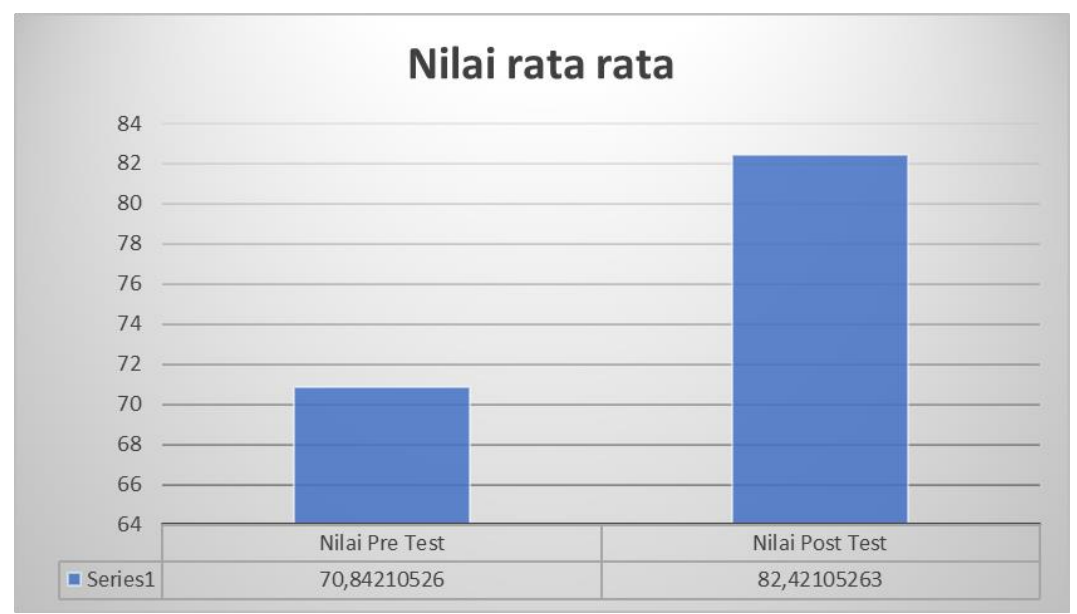

Gambar 1. Grafik rata rata nilai 
Kemudian untuk mementukan besarnya kenaikan hasil belajar sebelum dan sesudah eksperimen, maka perlu dilakukan uji gain (analisis nilai efektivitas dari penerapan metode belajar pada sebelum dan sesudah dilakukan penelitian). Perhitungan nilai gain, digunakan rumus sebagai berikut:

$$
\text { Gain ternormalisasi }(\mathrm{g})=\frac{\text { Skor posttest }- \text { skor pretest }}{\text { Skor ideal }- \text { skor pretest }}
$$

Gambar 2. Rumus Pengujian T test

Maka dari data pretest dan posttest, akan diuji gain dengan hasil perhitungan nilai gain dengan menggunakan SPSS.

\begin{tabular}{|c|c|c|c|c|c|}
\hline \multicolumn{6}{|c|}{ Descriptives } \\
\hline & Kelas & & & Statistic & $\begin{array}{l}\text { Std. } \\
\text { Error }\end{array}$ \\
\hline \multirow[t]{15}{*}{ Nilai Gain } & Kelas & Mean & & .4190 & .06496 \\
\hline & Eksperimen & $95 \%$ Confidence & Lower & .2825 & \\
\hline & & Interval for Mean & Bound & & \\
\hline & & & Upper & .5555 & \\
\hline & & & Bound & & \\
\hline & & $5 \%$ Trimmed Mean & & .4068 & \\
\hline & & Median & & .3000 & \\
\hline & & Variance & & .080 & \\
\hline & & Std. Deviation & & .28316 & \\
\hline & & Minimum & & .06 & \\
\hline & & Maximum & & 1.00 & \\
\hline & & Range & & .94 & \\
\hline & & Interquartile Range & & .36 & \\
\hline & & Skewness & & .833 & .524 \\
\hline & & Kurtosis & & -.295 & 1.014 \\
\hline Persen & Kelas & Mean & & 41.8978 & 6.49606 \\
\hline Gain & Eksperimen & 95\% Confidence & Lower & 28.2501 & \\
\hline & & Interval for Mean & Bound & & \\
\hline
\end{tabular}




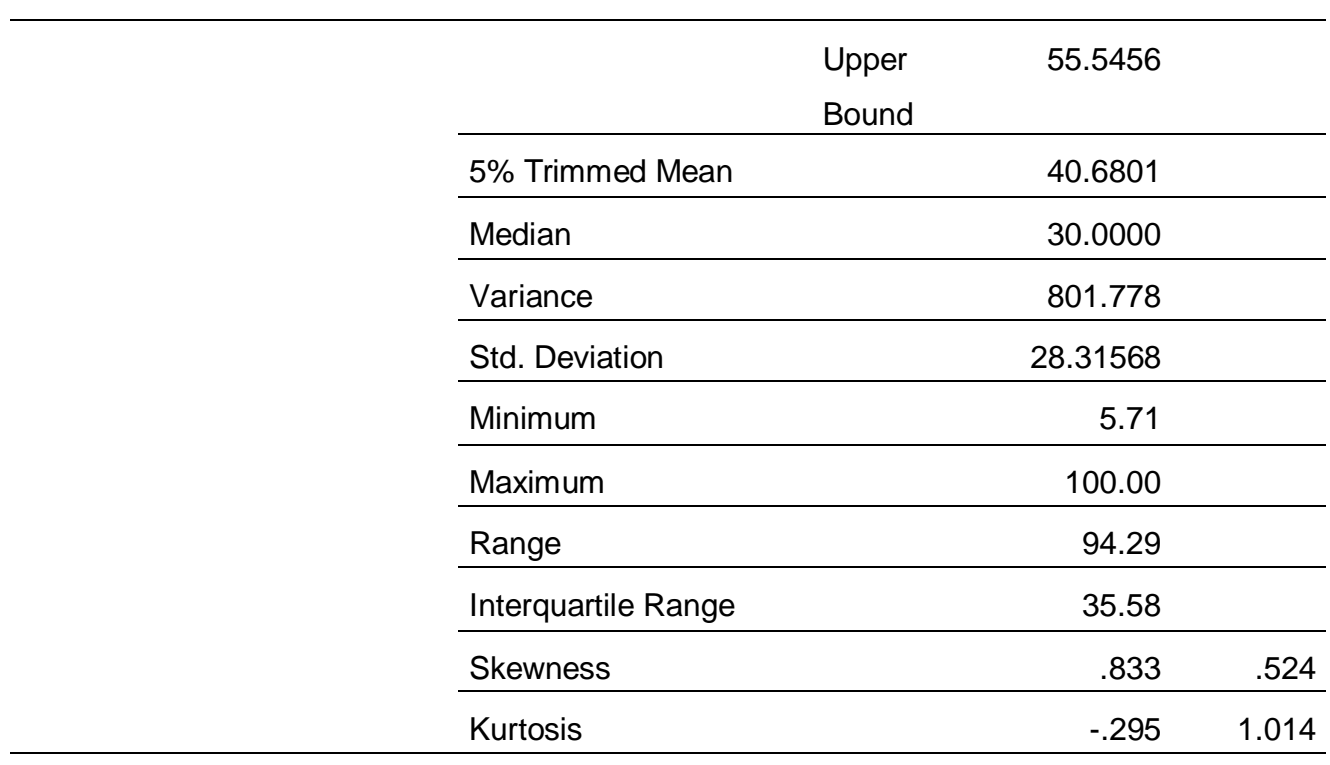

Tabel 6. Perhitungan Nilai Gain

Hasil pengujian nilai gain ternormalisasi akan diinterprestasi kan dengan tabel berikut :

\begin{tabular}{cc}
\hline Nillai Gain Ternormisasi & Interpretasi \\
\hline$-1,00<\mathrm{g}<0,00$ & Menurun \\
$\mathrm{G}=0,00$ & Tetap \\
$0,00<\mathrm{g}<0,30$ & Rendah \\
$0,30<\mathrm{g}<0,70$ & Sedang \\
$0,70<\mathrm{g}<1,00$ & Tinggi \\
\hline
\end{tabular}

Tabel 7. Interpretasi Nilai Gain Ternormalisasi (Sundayana, 2018)

Maka dari hasil pengujian gain ternormalisasi, didapatkan nilai gain sebesar 0.41 yang jika diinterpretasikan nilai gain tersebut berada pada efektivitas sedang dengan persentase kefektivitasan sebesar 41\%. Sehingga dapat disimpulkan bahwa metode Peer Reading efektif terhadap kemampuan 
pemahaman dokkai pada mahasiswa semester III Program Studi Pendidikan Bahasa Jepang FKIP UHAMKA.

\section{KESIMPULAN}

Penerapan Peer reading memberikan efektivitas terutama pada pembelajaran dokkai untuk semester III Pendidikan Bahasa jepang FKIP UHAMKA karena berdasarkan hasil rata rata nilai pretes dan postes, dapat diketahui bahwa nilai pretest sebelum diberikan treatment adalah sebesar 70,84 dan nilai posttest setelah diberikan treatment adalah 82,42 dengan nilai gain sebesar 0.41 maka teknik ini memiliki tingkat kefektivitasan sedang, sehingga dapat disimpulkan bahwa metode Peer Reading efektif terhadap pemahaman dokkai pada mahasiswa semester III Program Studi Pendidikan Bahasa Jepang FKIP UHAMKA.

\section{REFERENSI}

Harras, K. A. (2011). Hakikat dan proses membaca. Membaca 1. UT Press.

Kartini, S. (2012). Metode bercerita dalam pembelajaran menyimak di kelas V sekolah dasar. EduHumaniora Jurnal Pendidikan Dasar, 2(2). https://doi.org/10.17509/eh.v2i2.2766

Kusmayadi, I. (2008). Think smart bahasa Indonesia. Grafindo Media Pratama

Mulyati, Y. (2014). Hakikat keterampilan berbahasa. Jakarta: PDF Ut. ac. id hal, 1.

Rasiban, L. M., \& Dianasari, W. (2017). EFEKTIVITAS METODE PEER READING DALAM PEMBELAJARAN MEMBACA PEMAHAMAN (DOKKAI). JAPANEDU: Jurnal Pendidikan Dan Pengajaran Bahasa Jepang, 2, 9. https://doi.org/10.17509/japanedu.v2i1.6999

Sundayana, R. (2018). Statistika penelitian pendidikan. Penerbit Alfabeta.

Tarigan, H. G. (1986). Membaca sebagai suatu keterampilan berbahasa. Angkasa. 